\title{
Synthesis and Characterization of Shape Controlled Platinum Metal Catalyst
}

\author{
Kanimozhi R, Rajkumar V, Shabil John J P
}

\begin{abstract}
The catalytic and electro catalytic properties was determined by using size and shape of platinum nanoparticles. To produce well defined and controllable shapes of platinum nanoparticles and improve their performance in terms catalytic activity and selectivity many chemical methods has been developed. Synthesis of colloidal platinum nanoparticles in three different shapes by using polyol synthesis method, Polyvinylpyrrolidone (PVP) as a reducing agent in first method. Ethylene glycol has been used as a solvent and addition of silver ions for enhances the crystal growth. Sodium borohydride has been used as the reducing agent in the second method. Most of the papers silver nanoparticles were synthesized. In this paper we try the potassium chloroplatinate has to be reducing platinum nanoparticles by sodium borohydride. The same methods to be using a silver nitrate is convert to silver nanoparticles by using the same reducing agents.
\end{abstract}

Keywords :Colloidal Platinum nanoparticles, polyol synthesis method, $\mathrm{PVP}, \mathrm{NaBH}_{4}$

\section{INTRODUCTION}

Inorganic materials like metals have their specific properties and uses due to this have more attention in, and catalytic properties. Shape controlled particles was prepared in large volume with strategies of research side. In particular, Inorganic materials in which metal particles with different shapes from their bulk have different properties like electric, magnetic, optical cost effective in which shape controlled nanoparticles plays major role in future energy technology. Fossil fuels was substituted by shape controlled nanoparticles due to synthesizing energy and biomass. Metal particle have their application in the production of hydrogen from three different phases of energy carriers.Shape-dependent properties is one of the critical property plays major role in catalyst activities.

Many searchon going to find specific characteristics of modern science and technology which is going to be a new functional materials in future. In particular platinum particles are shape controlled metals have broad scope of numerous empirical demand. In many cases, according to this nano size range both chemical and physical properties were found. Platinum have layers have wide application in enzyme and also used for catalyticreaction.

Heterogeneous nanocatalysis is one of the most interest area in research due to the shape controlled metal particles amuse

Revised Manuscript Received on December 16, 2019

* Correspondence Author

First Author Name*, Kanimozhi R/Chemical engineering department, Kalasalingam Academy of Research and Education, Virudhunagar , India. Email: kanimozhi.ranga@gmail.com

Second Author Name, Rajkumar R ,Working in TNPL, Karur, India Email: rajveeraiyan@gmail.com

Third Author Name, Shabil John J P, Wood Design Company, Chennai, India. Email:Shabil.j.p@gmail.com critical part as formation - responsive to vital median. In Advanced nanotechnology, the design of metal NPs predominance in the field of well definednanocatalystmodels ,empirical correlation and in the mechanism of catalyst.

Shape controlled platinum nanocrystal metal shows the distinctive catalytic property .Depletion or putrefaction of the metal due to the existence of biological mantle reagents was methods are used to control dimensions of nanoparticles many methods are used such as reduction or decomposition of the metal precursor in the presence of organic capping reagents in solution. Regulating agents such as Cetyltrimethylaoniumbromide (CTAB) and Poly vinyl pyrrolidone(PVP) was chosen based on their shape of nanocrystals in the form of rods, prisms and cubes.

Usual forerunner used in platinum nanoparticles synthesis is potassium chloroplatinate $\left(\mathrm{K}_{2} \mathrm{PtCl}_{4}\right)$. The forebear is typically go into solution in an aqueous or organic liquid phase. Due to the effect of reducing agent there is chemical reaction taking place to convert aqueous liquid metal to soild metal. Other than chemical reaction there is a decomposition, displacement, or electrochemical reactions are also take place.

\section{MATERIALS AND METHODS}

For catalytic reduction $100 \mu \mathrm{l}$ of $\mathrm{p}$-Nitro phenol $(10 \mathrm{mM})$, $1 \mathrm{ml}$ of $\mathrm{NaBH}_{4}(0.1 \mathrm{M})$ and distilled water added in quartz cuvette. Then the following shape controlled platinum catalyst colloidal solutions were added at $50 \mu \mathrm{l}$ into the cuvette. PVP stabilized platinum nanoparticles.Honey stabilized platinum particles.Ascorbic acid stabilized platinum particles.Guar gum stabilized platinum particles.

After adding the catalyst the cuvette was put into the UV visible spectrophotometer and the strength of the absorption peak at $400 \mathrm{~nm}$ in the UV-visible spectrophotometer and it is handed down to monitor the conversion of p-nitrophenol to p-aminophenol .In here the powdered sample was converted into colloidal form by using ultrasonic cleaner. $20 \mathrm{mg}$ of powdered sample was taken into the conical flask then mixed with $10 \mathrm{ml}$ of distilled water. The conical flask was put into the ultra sonic cleaner using the frequency of $50 \mathrm{kHz}$ for 10 mins. 


\section{Synthesis and Characterization of Shape Controlled Platinum Metal Catalyst}

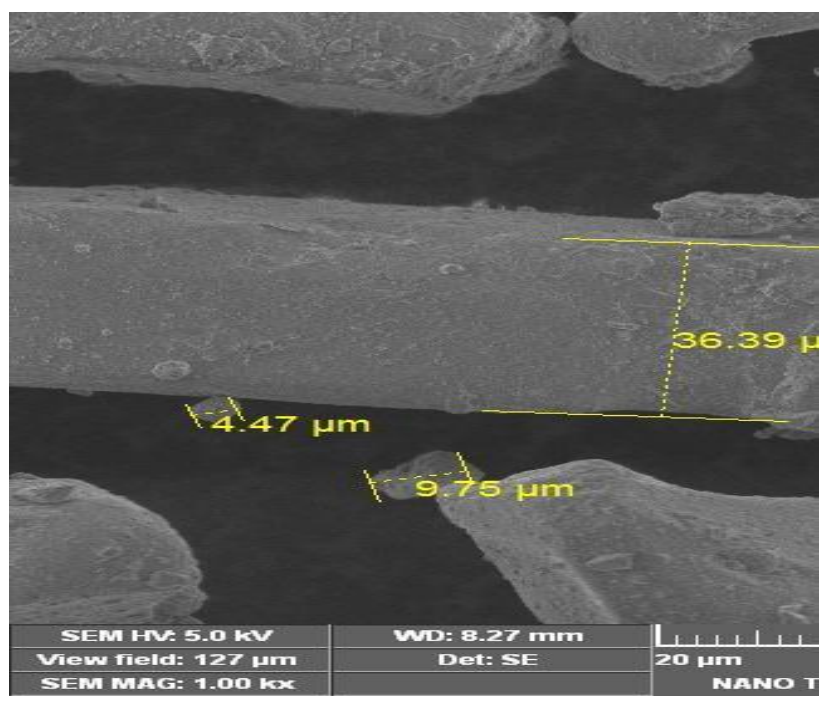

Fig. 1.SEM image of platinumprecursor

\section{III.RESULT AND DISCUSSION}

\section{A. Scanning Electron Microscopy(SEM)}

Scanning electron microscopy (SEM) examine the exterior of substance, molecule or atom and fibres so that exquisite feature can be calculated and evaluated via image analysis. SEM analyse used to find contamination issues in chemical industry, identify the failure component, study the interactivity between material and their substrates. It can also furnish a plenty of statistics to hold up research of substance, chemicals or organic samples. The process of explaining SEM images is not at all time simple and straight. The distinguishing of particulates, or the study of physical and chemical feature of substance was difficult task due to the interpretation of metal components and alsoSEMimages was not clear and direct. With the additional advantage to obtain primary constitution for the typical and smooth the research of substances and exterior facilitates with SEM/EDX. Distribution and elemental mapping across the surface of the sample is also available. The below images show the dimensions of the platinum nanoparticles by using the PVP as a reducing agent. Increasing the reducing agents ratio the size of the platinum nanoparticles was reduced. Image (a) represents the spherical particles of the platinum nanoparticles. Image (b) represents the cube shaped platinum nanoparticles..
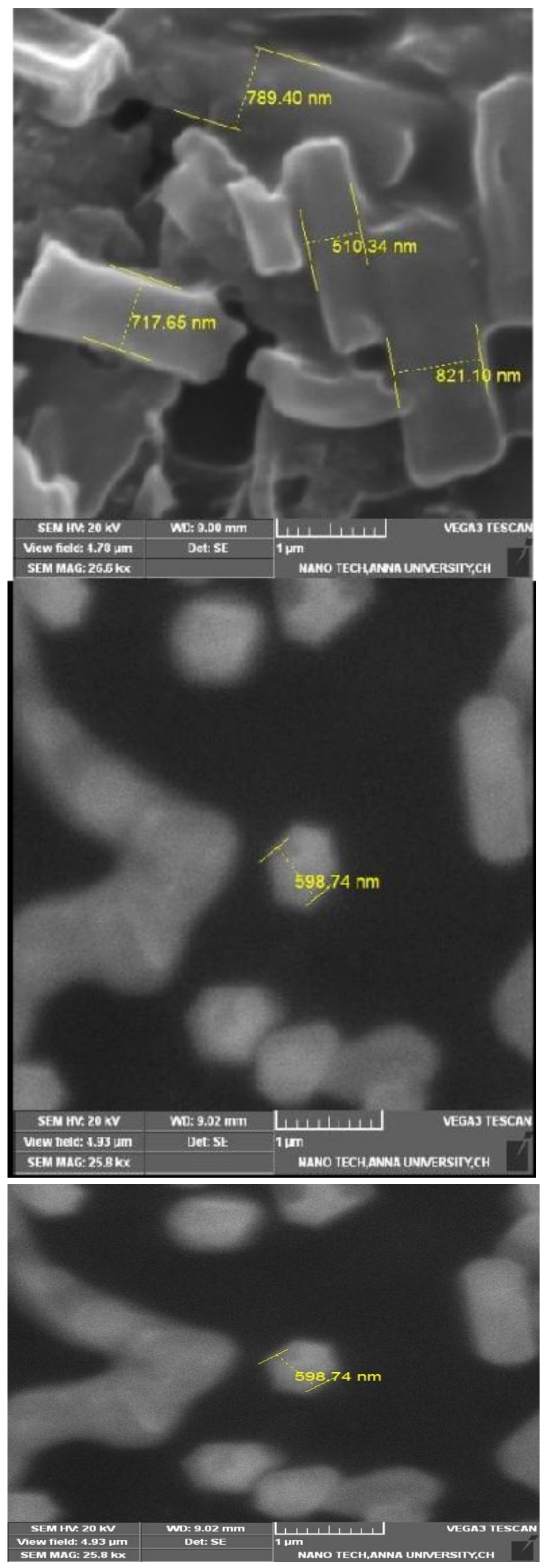

Fig.2. SEM images of platinum nanoparticles (a) $60 \mathrm{mg}$ (b) $40 \mathrm{mg}$ (c) $20 \mathrm{mg}$ of PVP 


\section{B. PVP as a Reducing Agent}

Table I.Results of platinum nanoparticles using PVP as a reducing agent

\begin{tabular}{|c|c|c|c|c|c|}
\hline \multirow{2}{*}{$\begin{array}{l}\text { Amount } \\
\text { Of } \\
\text { Reducing } \\
\text { agent(mg) }\end{array}$} & \multirow[t]{2}{*}{$\begin{array}{l}\text { Colour } \\
\text { of Final } \\
\text { Solution }\end{array}$} & \multirow[t]{2}{*}{$\mathbf{p H}$} & \multirow[t]{2}{*}{$\begin{array}{l}\text { Shape of } \\
\text { the Nano } \\
\text { particle }\end{array}$} & \multicolumn{2}{|c|}{$\begin{array}{l}\text { Size Of the } \\
\text { nanoparticles } \\
(\mathrm{nm})\end{array}$} \\
\hline & & & & Min & Max \\
\hline 20 & $\begin{array}{r}\text { Reddi } \\
\text { sh black }\end{array}$ & .7 & Hexagon & 74 & 598 \\
\hline 40 & $\begin{array}{r}\text { Green } \\
\text { ish black }\end{array}$ & .9 & $\begin{array}{l}\text { Rectangu } \\
\text { lar }\end{array}$ & 73 & 830 \\
\hline 60 & Black & $.5^{8}$ & spherical & 76 & 86 \\
\hline
\end{tabular}

\section{C.NABH 4 As A ReducingAgent}

The image shows the platinum nanoparticles by utilizing reducing agent such as $\mathrm{NaBH} 4$. Mostly $\mathrm{NaBH}_{4}$ was used to conglomerate of silver nanoscale particles. Here we tried platinum precursor. Image (a),(b) was not clearly shows any shape and size. Image (c) shows the nanowires of the platinum in nanometer size.

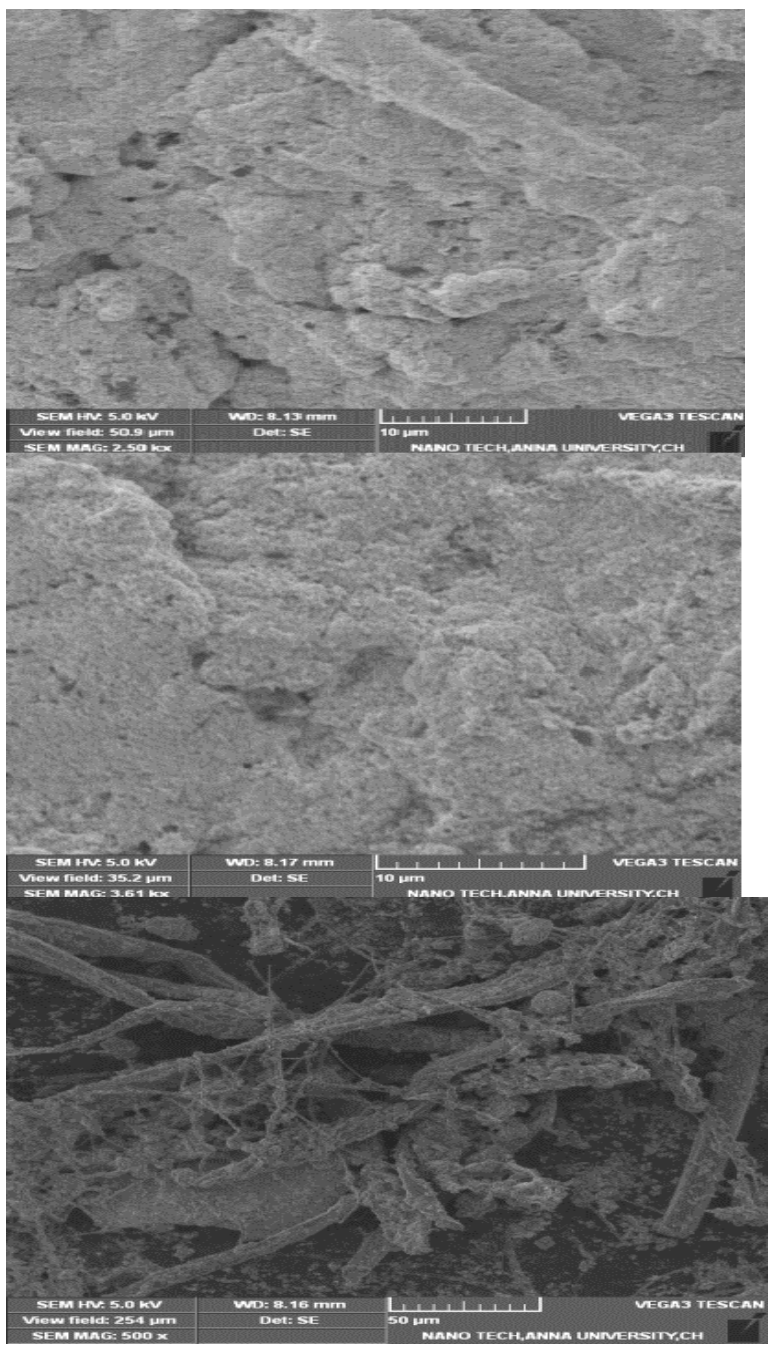
$\mathrm{NaBH} 4$

D. Honey as a reducingagent
Fig.3.SEM images of (a) $100 \mathrm{mg}$ (b) $80 \mathrm{mg}$ and (c) $60 \mathrm{mg}$ of

To prepare the wire shaped platinum particles, $20 \mathrm{~mL}$ of $0.01 \mathrm{M} \mathrm{K}_{2} \mathrm{PtCl}_{4}$ aqueous solution was prepared and then 5 grams of honey was added to the solution at last the solution was dissolved in $25 \mathrm{~mL}$ of distilled water. The prepared solution was sealed. The prepared dissolved solution was preheated in oven at $100{ }^{\circ} \mathrm{C}$ for $6 \mathrm{hrs}$.

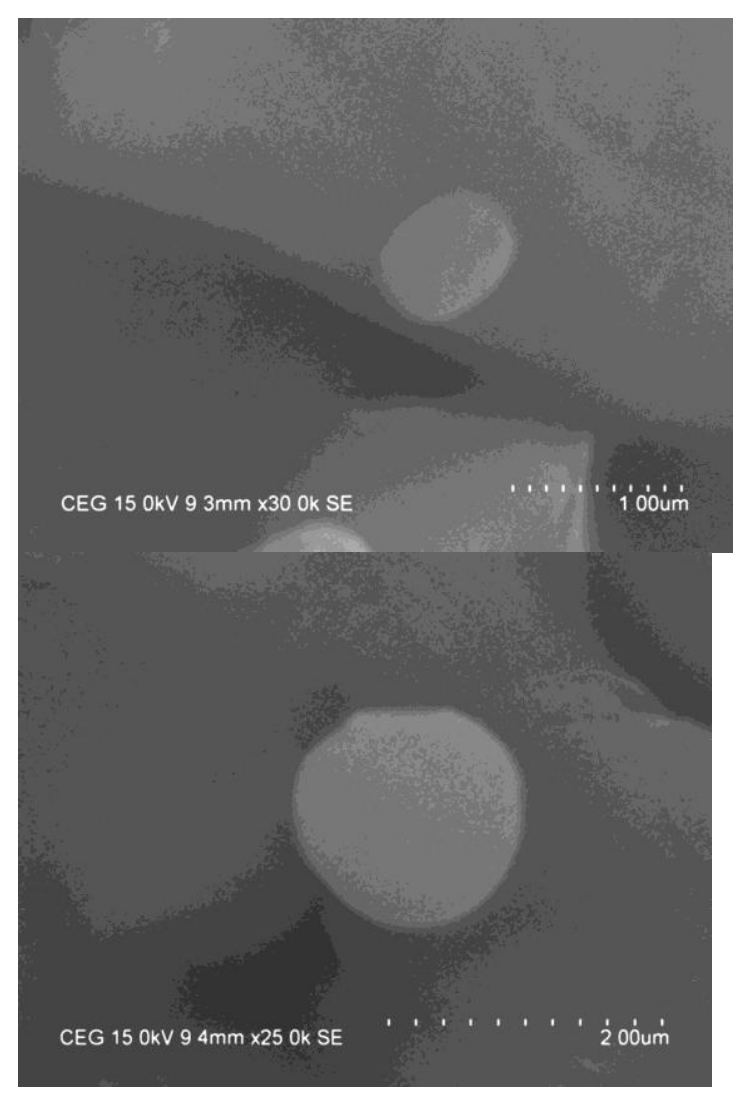

Fig. 4.SEM images of hyper branched platinum particles by using honey

\section{IV.CONCLUSION}

The above results shows that the catalyst efficiency changed depends on the shapes of the particles. From that the cub octahedral shaped platinum particles give more efficiency than the other shaped platinum particles, because the cub octahedral shapes having more surfaces than the others. Cub octahedral shaped platinum catalyst have 8 triangular and 6 cube shaped surfaces. In the process, reduction of p-nitrophenol into p-aminophenol cuboctahedral shaped platinum particles gives $68.8 \%$ conversion within the time period of 15 minutes.

\section{REFERENCES}

1. Dai,Yihu, et al. "Metallic nanocatalysis: an accelerating seamless integration with nanotechnology." Small 11.3 (2015):268-289

2. Figueiredo, Marta C., et al. "Carbon-supported shape-controlled Pt nanoparticle electro catalysts for direct alcohol fuel cells." Electrochemistry Communications 55 (2015):47-50.

3. Islam, Md Aminul, M. A. Bhuiya, and M.Saidul Islam. "A Review on Chemical Synthesis Process of Platinum Nanoparticles." Asia Pacific Journal of Energy and Environment 1.2(2014).

4. Pandey, Sadanand, and Shivani B. Mishra. "Catalytic reduction of p-nitrophenol by using platinum nanoparticles stabilised by guar gum."Carbohydrate polymers 113 (2014): 525-531.

5. Kang, Yijin, et al. "Shape-controlled synthesis of pt nanocrystals: the role of metal carbonyls." ACS nano 7.1

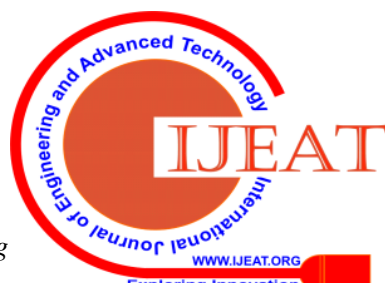




\section{Synthesis and Characterization of Shape Controlled Platinum Metal Catalyst}

(2012):645-653

6. Venu, R., et al. "Bio-directed synthesis of platinum nanoparticles using aqueous honey solutions and their catalytic applications." Colloids and Surfaces A: Physicochemical and Engineering Aspects 384.1 (2011):733-738.

7. Wang, Liang, et al. "On the role of ascorbic acid in the synthesis of single-crystal hyperbranched platinum nanostructures." Crystal Growth \& Design10.8 (2010):3454-3460.

8. Chen, Jingyi, et al. "Shape-controlled synthesis of platinum nanocrystals for catalytic and electro catalytic applications." Nano Today 4.1 (2009):81-

9.5

\section{AUTHORS PROFILE}

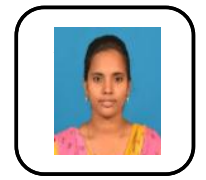

Kanimozhi $\mathbf{R}$ has completed B.Tech in Chemical Engineering and $\mathrm{M}$. Tech in chemical engineering. Published one paper in International Journal of Engineering Research and Development. Currently working as Assistant professor in department of Chemical

education. Engineering in Kalasalingam Academy of Research and

RajKumar $\mathbf{V}$ has completed B.Tech in Chemical Engineering and $\mathrm{M}$. Tech in chemical engineering. He is currently working as Engineer in TNPL.

Shabil John J Phas completed B.Tech in Chemical Engineering and $\mathrm{M}$. Tech in chemical engineering. He is currently working as Process Engineer in Wood. 